\title{
The Nia Project-Brief
}

Eunice N. Muthengi

Population Council

Emily Farris

Karen Austrian

Population Council

Follow this and additional works at: https://knowledgecommons.popcouncil.org/departments_sbsr-pgy

Part of the Demography, Population, and Ecology Commons, Family, Life Course, and Society Commons, International Public Health Commons, Maternal and Child Health Commons, and the Women's Health Commons How does access to this work benefit you? Let us know!

\section{Recommended Citation}

Muthengi, Eunice N., Emily Farris, and Karen Austrian. 2017. "The Nia Project," brief. Nairobi: Population Council. 
The onset of puberty and menarche is a particularly vulnerable time for girls, a time when they begin to show interest in the opposite sex and also become exposed to a myriad of external pressures, including sexual coercion or harassment from boys and men, expectations to marry from their families, and the need to perform well in primary school in order to qualify for secondary school. These pressures can be exacerbated by girls' lack of knowledge of their bodies, their rights, and the implications of their decisions, and by their inability to manage puberty and adolescence safely and comfortably with appropriate menstrual health and hygiene management (MHM) products.

While several programs have previously been developed to address girls' MHM needs globally, few have been evaluated, and where evidence does exist the results have been mixed. Reviews of these studies indicate that there is a lack of rigorous studies demonstrating the effect of MHM on girls' general health and well-being.

In collaboration with ZanaAfrica, the Population Council is evaluating the Nia Project, a set of interventions for adolescent girls in Kilifi County, Kenya. Using a randomized controlled trial (RCT) research design, this evaluation analyzes the effect of distribution of Nia brand disposable sanitary pads and provision of reproductive health education (i.e., facilitated sessions and the Nia Teen magazine) on girls' education and reproductive health outcomes.

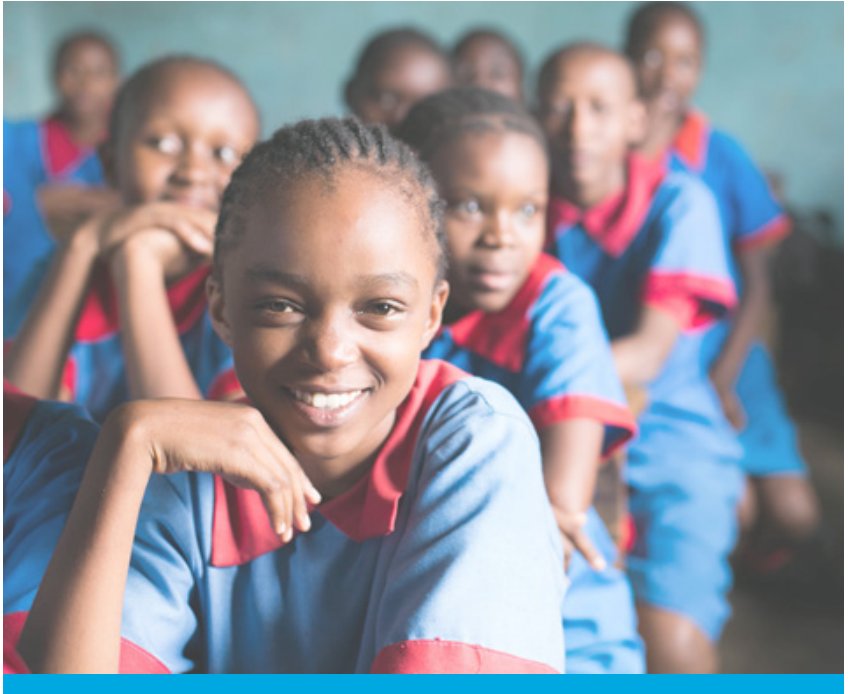

This brief presents data from the baseline survey of the Nia Project, providing a multidimensional description of a sample of the girls who will be participating in the $\mathrm{Nia}$ Project and the schools they attend. The sample includes 3,489 girls from 140 schools in three rural Kilifi subcounties: Magarini, Kaloleni, and Ganze.

\section{Study design}

\begin{tabular}{|c|c|c|c|}
\hline Arm 1 & Arm 2 & Arm 3 & Arm 4 \\
35 schools & 35 schools & 35 schools & 35 schools \\
\hline $\begin{array}{c}\text { Control } \\
\text { (No intervention) }\end{array}$ & Sanitary pads & $\begin{array}{c}\text { Reproductive health } \\
\text { education }\end{array}$ & $\begin{array}{c}\text { Reproductive health } \\
\text { education }\end{array}$ \\
\hline
\end{tabular}




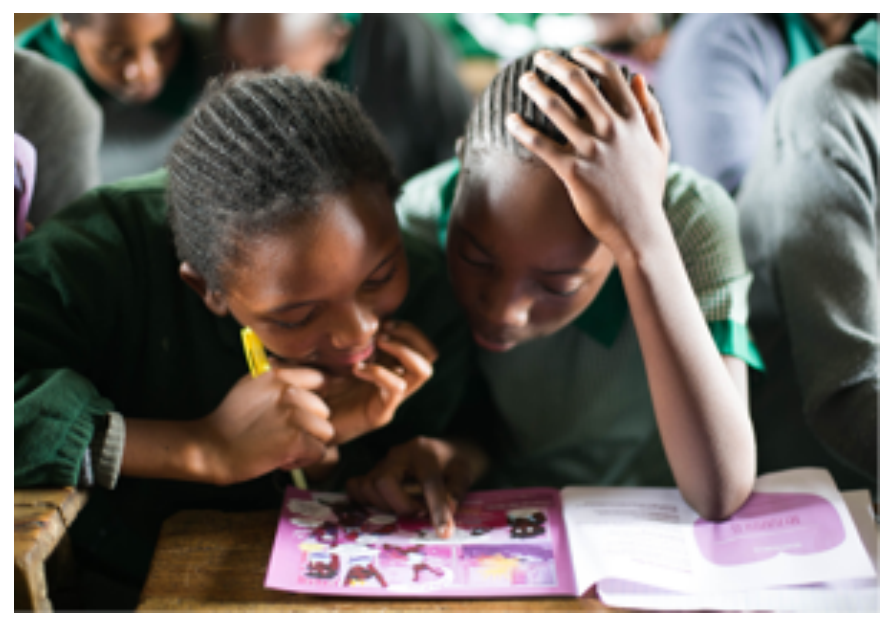

\section{Key findings}

\section{Schooling}

Findings describe a cohort of Class 7 girls between 10 and 21 years of age, with high educational aspirations despite anticipated challenges, and substantial parental approval for education despite low levels of parental education. While most girls believe they are capable of doing well in school, a gap exists in some of the social and personal competencies that would empower them to complete secondary education and even continue to tertiary education.

\section{Menstruation}

Although girls have some access to disposable sanitary pads, a significant need for products to manage menstruation still exists, demonstrated by the large proportion of girls who report that they do not have enough pads, and those who did not receive pads in school in the previous term. In addition, girls shared feelings of shame and discomfort regarding their period that can potentially be improved by the group meetings and magazine.

- $79 \%$ of girls do not have enough materials to manage their menstruation comfortably

- $54 \%$ of girls received sanitary pads at school during the last term

\section{Reproductive Health}

Relatively low scores on the self-efficacy and decision-making scales, together with inequitable

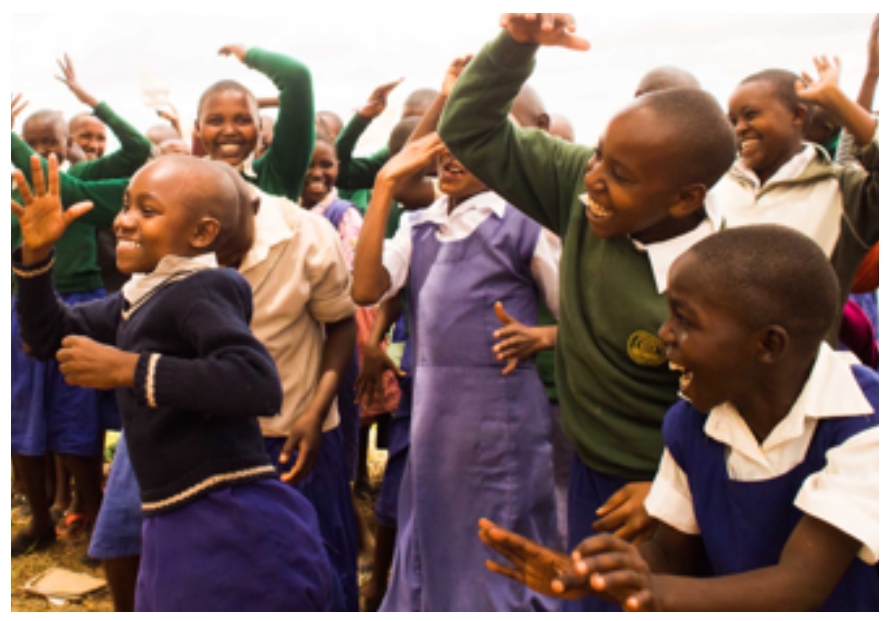

gender norms and a high justification of intimatepartner violence, suggest that substantial room for improvement exists through the Nia reproductive health education component to positively affect the girls. About a tenth were sexually experienced, and half of those reported their first sex as unwanted. Girls who had already initiated sex reported inconsistent condom use and very low use of other contraceptive methods, putting them at high risk of pregnancy and STIs, and increasing their likelihood of stopping their education.

\section{Conclusion}

While gaps exist in girls' capabilities, particularly knowledge and attitudes related to menstruation and reproductive health, the Nia Project has the potential to bridge those gaps. The Project is one of the first RCTs to explore the role of sanitary pad distribution and reproductive health education-individually and in combination-to improve girls' educational and sexual and reproductive health ( $\mathrm{SRH}$ ) outcomes. The findings of this study will make a critical contribution to filling an evidence gap in the field of $\mathrm{MHM}$, and in doing so will guide education and health policy in this area in Kenya and in the region.

See The NIA Project: Baseline Report, http://www.popcouncil.org/uploads/pdfs/ 2017PGY_NiaProjectBaseline.pdf (forthcoming)

(C) 2017 The Population Council, Inc. 